\title{
Talking about Leaving Revisited Persistence, Relocation, and Loss in Undergraduate STEM Education
}

\author{
Book Review by David Bressoud
}

\section{Talking about Leaving Revisited: Persistence, Relocation, and Loss in Undergraduate STEM Education Elaine Seymour and Anne-Barrie Hunter, Editors Additional authors: Heather Thiry, Tim Weston, Raquel Harper, Dana Holland, Andrew Koch, and Brent Drake}

In 1997, Seymour and Hewitt published Talking about Leaving: Why Undergraduates Leave the Sciences [7]. Based on an extensive body of research, they revealed a constellation of factors that lead students to drop out of STEM ${ }^{1}$ majors. Beyond inadequate preparation, they uncovered reasons that included poor teaching, curriculum overload, inadequate advising and support, and rejection of the highly competitive culture these students encountered in their major.

Given the increasing importance of a workforce prepared for STEM careers, the community of those working to improve undergraduate mathematics education have awaited this follow-up study with considerable anticipation. Led by Anne-Barrie Hunter and funded by the Alfred P. Sloan Foundation and the National Science Foundation, a team of researchers at the University of Colorado Boulder undertook a detailed and comprehensive study of student attraction to and retention in STEM. Their work, presented in this volume in a series of reports, is based on triangulated

David Bressoud is DeWitt Wallace Professor of Mathematics at Macalester College and director of the Conference Board of the Mathematical Sciences. His email address is bressoudamacal ester. edu.

This review draws on parts of an essay written by the author for MAA "Launchings," posted at MathVa7ues.org, and it is published here with permission from the MAA.

${ }^{1}$ For the study reported in this volume, STEM consists of agriculture, environmental science, computer and information sciences, engineering, biological and life sciences, mathematical sciences, and physical sciences.

For permission to reprint this article, please contact: reprint-permission aams.org.

DOI: https://dx.doi.org/10.1090/noti 2145 results from in-depth analyses of institutional records, classroom observations, surveys, focus groups, and individual interviews undertaken over the period 2012-2017 at six institutions: four large public R1 universities, one private R1 university, and one liberal arts college.

\section{The Challenge for the Future}

We are losing large numbers of prospective STEM majors. If we compare the number of students who enter college with the intention of majoring in a STEM ${ }^{2}$ field with those who earn a bachelor's degree in STEM each year, we see that there is a widening gap (Figure 1). The situation is, in fact, worse than this graph indicates because the count of intended majors includes only those who begin as full-time students in a four-year undergraduate program. The graph of actual graduates also counts those who started in a twoyear program and those who began as part-time students.

An important observation from this figure is that from 1975 until 2007, the number of entering students intending a STEM major stayed remarkably consistent, dropping in the mid-1980s, then growing by a bit over $50 \%$ over the next twenty years. From 2007 to 2017, the number doubled. The change in slope was so abrupt that the economic uncertainties unleashed by the Great Recession of 2008-09 must have been a significant factor.

This book investigates who is leaving and why, with particular focus on women and underrepresented minorities. As in the original study published in 1997, findings from the new study counter the common presumption that most students who leave STEM majors do so because they are unable to meet the intellectual challenges or work

\footnotetext{
${ }^{2}$ These graphs are based on the number of students in biological or life sciences, computer or information sciences, engineering, mathematical sciences, or physical sciences. They do not include those in the agricultural sciences.
} 


\section{EDUCATION}

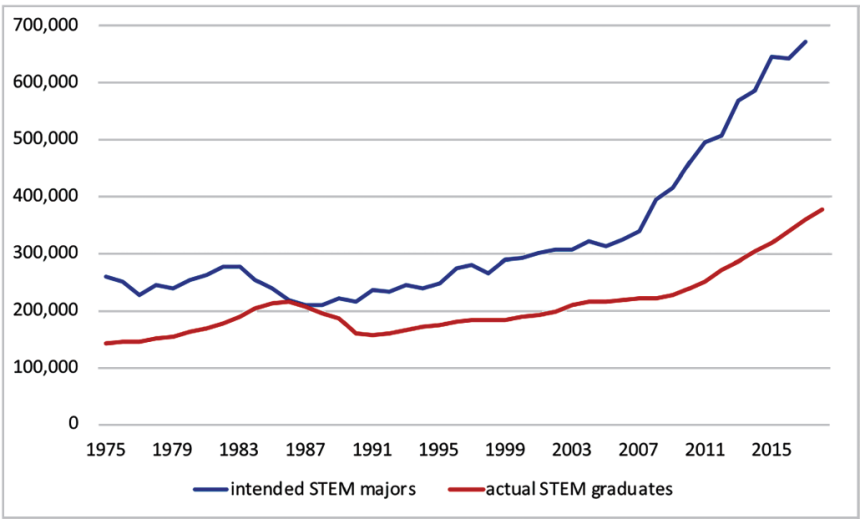

Figure 1.The number of full-time first-year students at four-year undergraduate programs intending to major in a STEM field (upper blue graph) against the number of students graduating with a bachelor's degree in a STEM field that year (red). Sources: Higher Education Research Institute (HERI) [4] for the blue graph and National Center for Education Statistics (NCES) [5] for the red.

demands of a STEM curriculum. This study found that $10 \%$ of those who declared and then left a STEM major had an ACT math score of at least 31 or an SAT math score of at least 681 . Almost a third, 32\%, of those who left their STEM track had entered with an ACT math score of at least 28 or an SAT math score of at least 621. A substantial section of this study looks at how and why high-performing students (those whose GPA in their first semester at college is 3.5 or higher) leave STEM. As revealed in the MAA's calculus studies [2] and further substantiated here, losses of women are especially problematic.

While women now constitute $57 \%$ of all bachelor's degrees, they make up only $40 \%$ of those in the physical sciences, $22 \%$ in engineering, and $20 \%$ in computer science. In the mathematical sciences, they compose $42 \%$, which may seem acceptable but is down from a high of $48 \%$ in $2001 .^{3}$

Perhaps the greatest challenge comes with underrepresented minorities. ${ }^{4}$ In 2000, they earned $15 \%$ of all bachelor's degrees. By 2018, this was up to 27\%. Yet in that year they represented only $23 \%$ of computer science majors, $21 \%$ of physical science majors, $18 \%$ of engineering majors, and $18 \%$ of mathematical science majors. However, viewing this as a racial/ethnic problem is misplaced. As stated in the final chapter of this book,

Focusing on race/ethnicity as if it were a significant independent variable appears to be inherently, if unintentionally, racist. The characteristics that create what appear to be issues related to race/ethnicity are more accurately

\footnotetext{
${ }^{3}$ Data from NCES (2018) [4, tables 322.30 and 322.50].

${ }^{4}$ These percentages are from NCES (2018) [4, table 322.30]. They combine the data for the classifications African American, Hispanic, Pacific Islander, American Indian, Alaskan Native, and two or more races.
}

issues of socio-economic and educational disadvantage. (p. 439)

This volume aims to move beyond simplistic labels and to identify the range of issues that impact students coming from a variety of backgrounds and experiences.

\section{Problems of the Transition}

In the chapter on "Issues with high school preparation and transition to college," the authors describe the common experience of many students, especially those from under-resourced schools, who had been able to coast by relying on memorization, maintaining high grades with little or no effort. They arrived in college without the study skills they needed to succeed and with a fragile sense of their readiness for a STEM career that was based on the high grades they had received in high school.

One of the longest chapters, "Weed-out classes and their consequences," is devoted to describing what happens when students encounter these prerequisite courses in their first year. The authors formally designate Severe Foundational Courses (SFCs) as classes of 100 or more students in the first or second year, in existence for more than four years, required and/or a prerequisite for a STEM major, and in which the percentage of students receiving a D, F, Withdraw, or Incomplete exceeds $20 \%$. An astonishing $67 \%$ of all students who were surveyed about their SFC reported that they learned little or no new content in this course (p. 210).

The impact of these courses-the authors point especially to Calculus and General Chemistry-is so severe that these reports retain the term "weed-out class" in discussing them. They can be devastating, especially for women and economically disadvantaged students. As one woman who completed a mathematics major reported her own experience,

The weed-out courses are trying to get rid of students rather than bring everyone along-it's psychologically crushing if you are in a class where you know their one objective is to get rid of you. (p. 229)

The reports in this book align with the findings of the calculus studies undertaken by the Mathematical Association of America [1, 6]: the teaching style in these courses is generally lecture-based and impersonal, grades are low, and these grades are often assigned on a curve with an implicit-and sometimes explicit-expectation that a certain percentage will fail.

This book chronicles the highly competitive environment in these courses, one that deters many students, especially women and students from underrepresented minorities who are already struggling against stereotype 
threat. As this volume documents, even a B can be discouraging for some women.

By men's and women's accounts, high-performing women struggled more to adjust to the weed-out practices that are a trademark of gateway STEM courses. (p. 365)

As the data presented in Figure 2 demonstrate, the greatest discrepancy between persistence rates of men and women occurs among those with the highest grade point averages (GPAs).

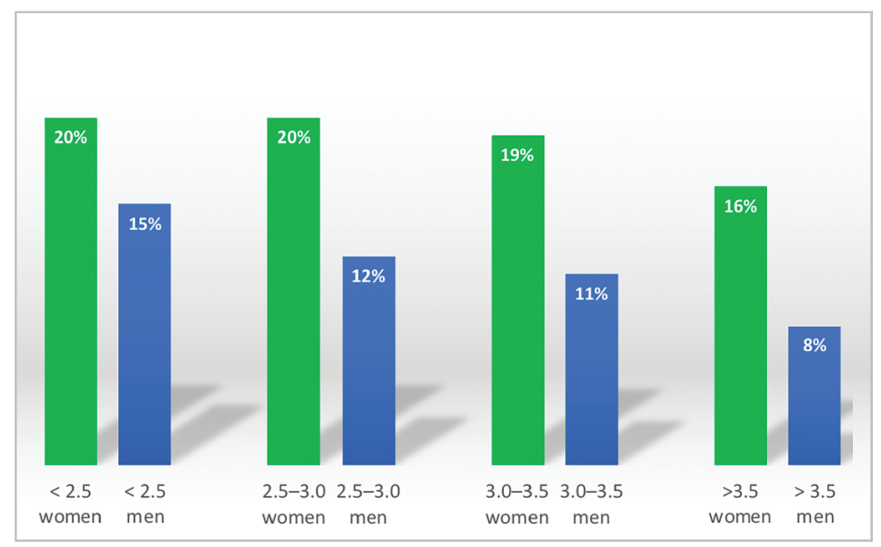

Figure 2. Rate of switching by gender and first-semester GPA. Source: Talking about Leaving Revisited, p. 70. Of the 5,696 women and 8,864 men who declared a STEM major at one of the six study sites, 1,041 women and 979 men subsequently switched to a non-STEM major.

Many women misinterpret moderate grades as failure. Being at the top of their high school class in science and mathematics was an important contributor to their decision to pursue a degree in a male-dominated field such as computer science, engineering, or physics. Given the prevalence of fixed mindset, that one either is or is not a "math person," the authors chronicle how experiences that create doubt can be deeply discouraging.

The authors do not advocate inflating grades. Rather, they call on instructors and advisors to be sensitive to the effects that grades have on different populations of students. This is especially true of the practice of grading on a curve.

The authors describe how being assessed "not in absolute terms by demonstrating conceptual understanding but relative to your classmates was novel and alarming" (p. 291). Even without predetermined grade distributions, the low raw scores fostered questioning whether one belonged.

I shoot for A's usually, but ... but they curved the class a lot .... and it didn't really feel like you were excelling when you were getting low grades on the test freshmen year. You don't understand how college classes curve and when you're getting like a 67 or 70 something on the test, it just doesn't feel good to you. It feels like you're failing almost. (p. 340, white woman, switched from biology to sports medicine)

Grading on a curve accentuates the uncertainties that confront many women.

Girls I normally work with, they got 4.0s in high school. In my fluid dynamics class, if you get a 70 overall, it's an $\mathrm{A}$, and he makes the tests so that the average is supposed to be like a 50. And so, even though they got a 55 and it's above average, they still couldn't wrap their heads around it. They would always freak out ... I definitely see that a lot more with girls-that perfectionism that they get from high school, where they need to get a 100 on everything. (p. 341, white man, graduated in chemical engineering)

These students capture the serious consequences of assessments that are pitched at an inappropriate level and then "corrected" by grading on a curve.

In the closing paragraphs of the Foreword to Talking about Leaving Revisited (TALR), Shirley Malcolm, head of education and human resources programs at AAAS, writes,

The constellation of factors that contribute to loss are broad and interconnected. Likelihood of poor K-12 schooling which so disadvantages students of color links to socioeconomic status and lack of social capital, lack of knowledge about careers or about navigating college. No single intervention can address this-only systemic approaches.

The harmful actions may not have been done with malice, but there has been and continues to be harm ... TALR makes the case for systemic change, pointing us to actions that can positively affect STEM for all. This is an opportunity to use the research to guide our actions, to reject the traditions born of a different time, place, and talent pool, letting TALR guide the path forward. (p. x)

Nothing illustrates what is needed in the first year, especially for women and those from economically disadvantaged backgrounds, better than the chapter titled "Getting an A" from Tough's important book, The Years That Matter Most: How College Makes or Breaks Us [8]. This chapter from his book demonstrates how devastating it can be for a talented and capable student from an under-resourced high school to encounter Calculus I for the first time at a large research university. Tough's chapter also illustrates what it takes to make it possible for this type of student 
to succeed. The solution is not to lower standards but to meet the essential needs for proper guidance, support, and encouragement.

\section{Perceptions of Teaching}

Poor-quality STEM teaching, particularly in introductory courses, still tops the list of student concerns, both from those who drop out of a STEM major (96\% of whom voiced this concern) and those who completed their STEM degree (72\% raised this issue). In the chapter on "Student responses to problematic STEM teaching methods," the most common complaint was disorganized and impersonal delivery, often accompanied by inappropriate pacing. This could be too slow, expanding on unimportant details, or too fast, racing through important concepts without giving students time to absorb what was essential. Students also reported problems with inappropriate level, represented by the following student quote.

The worst professors that I've experienced have actually been some of the smartest. I realize that they're experts in their field; they're really excellent at what they do ... but they're unable to simplify things in ways that they can express to students ... They will look at me and not be sure why I'm confused. And I'm confused why they don't understand that I'm confused. And it's just an ongoing cycle of that. I think it's a lack of knowing how to express really detailed concepts in a baseline way. (p. 163, white woman, graduated in neuroscience)

A purely lecture format was a big obstacle for many students. Students reported that lectures were often dull and spiritless, provided little opportunity for questions or discussion, and often failed to provide context by connecting the material to real-world phenomena.

It was just rambling — not many examples and all theory. And I realize it's math, but we're engineers and we need the examples of how to apply it. (p. 169, Asian woman, graduated in electrical engineering)

Over a third of those who left STEM reported encountering instructors who exhibited destructive behaviors, including those who were condescending, antagonistic, or even mocking of students. At a less egregious level were those who did not seem to care.

Of all the classes that I really disliked, the one thing that links them all is that you can tell that the professors didn't really enjoy what they were doing. (p. 172, Hispanic man, graduated in biological sciences)
One significant change from the 1997 report was that many students were now encountering active forms of instruction. Especially among women, their descriptions of "good" teaching included active and inquiry-based learning. Students reported that this improved their understanding of concepts, heightened their interest in the material, held their attention, and facilitated making connections between ideas.

As the authors explain in their chapter on "Students' perceptions of good STEM teaching," good teaching is more than just the absence of bad practices. Good teachers create organized, coherent courses. Students described good teachers as the ones who provided examples, showed applications, and made connections. Foremost among descriptions of good teaching were openness, approachability, and concern for students' learning.

Good professors acknowledge that some things are hard ... They look you in the eye and they're like, "This is hard stuff. This is hard to understand ... I'm open to talk about this after hours." They have open office hours ... and they make sure everybody is on the same page ... They're invested in your success. (p. 251, white woman, graduated in geosciences)

As Fairweather has pointed out [3, p. 10], the greatest gains in effective teaching come not from improving the practices of the good teachers, but by increasing the sensitivity of all faculty to the needs of their students and getting them to employ any form of pedagogy that increases student engagement.

\section{Lessons Learned}

The penultimate chapter provides student responses to the question, "What enables persistence?" First on the list was developing a balanced life. Students with interests outside of STEM were better able to cope with the pressures. Developing effective learning habits was also important. This included learning to ask for help, adapting to the different demands of different courses, and just accepting that studying was going to take a lot more effort than it did in high school. Persistence also meant adjusting to lower grades, that a 4.0 GPA may not be attainable in college, and B's, even C's, can be acceptable.

In addition, the authors' conversations with students revealed the importance of community and a sense of belonging. When all else was working against them, this source of support often kept students moving forward.

In the concluding chapter, the authors point to the importance of curriculum design, pedagogical methods, and assessments. They point out that even modest moves toward instructional strategies that have been studied and supported by research in STEM education can improve student outcomes, but they caution that we must first 
understand how individual instructors conceptualize the learning process. Many instructors still believe in "fixed intelligence" and that only the "innately gifted" are likely to succeed. They are poorly prepared to make the effort required to support those struggling with the transition to college.

The authors' message to the mathematics community is that employing Calculus as a "weed-out" course, whether intentionally or not, is especially destructive for first-generation college students and those from economically disadvantaged backgrounds. How it is taught and how at-risk students are supported require serious attention.

As the reports in this book reveal, the obstacles to success are far more varied and complicated than simple lack of ability. Moreover, they can be overcome if they are recognized and addressed. The first step is to understand the student experience at one's own institution. Who is succeeding - not just passing but preparing for future successes-and who is not? What is working and for whom, and what is not and for whom?

The chapters of this volume illustrate the kinds of data and information that each institution should be gathering, ranging from general statistics to surveys and interviews. The appendices include the survey instrument and the interview protocols that were used to gather the detailed information for this study.

The solutions to meeting the needs of the future will require systemic change. Those in authority-senior faculty, chairs, deans, provosts, and college presidents-must accept that high-quality teaching and the scholarship of teaching and learning are essential to their mission. Especially in this time of stretched resources and widening gaps between the privileged and the disadvantaged, we must embrace our collective responsibility to understand the full extent of the challenges that students face and to take steps, however constrained, toward addressing them. Talking about Leaving Revisited provides a template for gathering this information and a guide toward the actions that can be taken.

ACKNOWLEDGMENTS. This review has benefited from correspondence with Hunter and Seymour and the many helpful suggestions from the referees.

\section{References}

[1] D. Bressoud, V. Mesa, and C. Rasmussen (eds.), Insights and Recommendations from the MAA National Study of College Calculus, MAA Notes, Mathematical Association of America, Washington, DC, 2015.

[2] J. Ellis, B. K. Fosdick, and C. Rasmussen, Women 1.5 Times More Likely to Leave STEM Pipeline after Calculus Compared to Men: Lack of Mathematical Confidence a Potential Culprit, PLoS ONE 11 (2016), no. 7, e0157447, DOI 10.1371 /journal.pone.0157447.
[3] J. Fairweather, Linking Evidence and Promising Practices in Science, Technology, Engineering, and Mathematics (STEM) Undergraduate Education: A Status Report for The National Academies National Research Council Board on Science Education, 2009, sites.nationalacademies.org/dbasse/bose /dbasse_080106.

[4] Higher Education Research Institute (HERI), The American Freshman, Higher Education Research Institute, UCLA, Los Angeles, heri.ucla.edu/publications-tfs

[5] National Center for Education Statistics (NCES), Digest of Education Statistics, US Department of Education, Washington, DC, nces.ed.gov/programs/digest

[6] C. Rasmussen, N. Apkarian, J. Ellis Hagman, E. Johson, S. Larsen, D. Bressoud, and the Progress through Calculus Team, Characteristics of Precalculus through Calculus 2 programs: Insights from a national census survey, Journal for Research in Mathematics Education 50 (2019), no. 1, 98-112.

[7] E. Seymour and N. M. Hewitt, Talking about Leaving: Why Undergraduates Leave the Sciences, Westview Press, Boulder, CO, 1997.

[8] P. Tough, The Years That Matter Most: How College Makes or Breaks Us, Houghton Mifflin Harcourt, Boston, MA, 2019, www. pau1 tough. com/books/years-thatmattermost.

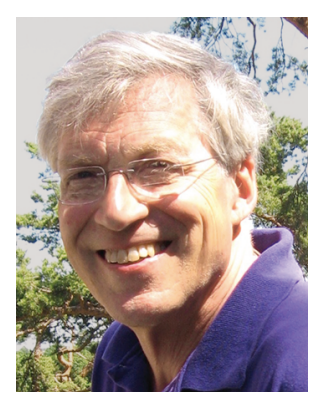

David Bressoud

\section{Credits}

Figures are courtesy of the author. Author photo is by Jan Bressoud. 